\title{
One-year monthly survey of rotavirus, astrovirus and norovirus in three sewage treatment plants in Beijing, China and associated health risk assessment
}

\author{
X. Q. He, L. Cheng, D. Y. Zhang, X. M. Xie, D. H. Wang and Z. Wang
}

\begin{abstract}
To evaluate the presence and distribution of the three main viruses (rotavirus, astrovirus, and norovirus) responsible for human acute gastroenteritis in sewerage system an one-year study was carried out in Beijing, China. A total of 96 samples of influent and effluents from three sewage treatment plants (STPS) were collected from November 2006 to October 2007. Silica was used to concentrate viral particles from water samples and a reverse transcriptase-nested polymerase chain reaction (RT-nested PCR) method was used for detection of viruses. Viruses could be detected in $35.4 \%$ (34/96) of the water samples analyzed, where human rotavirus was the most frequently detected $(32.3 \%, 31 / 96)$, followed by human astrovirus $(6.3 \%, 6 / 96)$ and human norovirus $(3.1 \%, 3 / 96)$. According to the quantitation results of rotaviruses, which were gained by the real-time quantitative RT-PCR method with SYBR Green I , it was known that the distributions of rotaviruses in influents and effluents of three STPS were quite similar, i.e., abundant in cold weather (from October to March) and less prevalent in warm weather (from April to September). According to the estimated exposure dose, exposure frequency, as well as the acceptable annual risk level, it was shown that the rotaviruses in the reused wastewater after conventional treatment process presented potential risk to human health through both occupational and

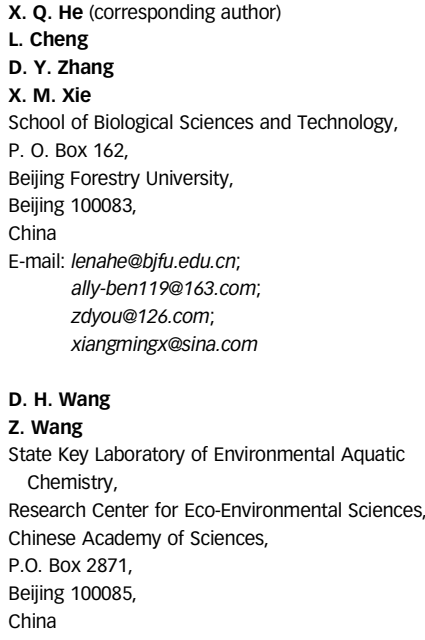
accidental exposure.

Key words | astrovirus, health risk, norovirus, rotavirus, STP

\section{INTRODUCTION}

Enteric viruses play an important role in pediatric diarrhea during the winter season in China. The reported frequencies of infection by rotavirus, astrovirus, and norovirus were $59 \%$, $8 \%$ and $6 \%$, respectively, during the winter season (from December 2000 to March 2001) in Beijing Children's Hospital (Liu et al. 2006). The infection was most commonly seen among children $<5$ years old hospitalized with acute diarrhea (Zhang et al. 2007) and 96.8\% of children were infected under 3 years of age (Tong et al. 2003). The number of deaths caused by rotavirus diarrhea accounted for $40 \%$ of all diarrhea deaths and $11.1 \%$ of the total deaths. Astrovirus seemed an important etiologic agent in young children with acute diarrhea in China, and over 95\% of astrovirus infections occurred in children before 2 years of age in seven regions of China during 1998-2005 (Fang et al. 2006). Norovirus was one of the important pathogens causing acute gastroenteritis outbreaks among infants and young children from January 2002 to December 2006 in Beijing Children's Hospital (Deng et al. 2007), which also caused outbreaks of acute gastroenteritis in six hospitals of Beijing from November to the end of 2006 (Jia et al. 2007).

Enteric viruses are able to persist under environmental conditions, and the release of infectious viruses into the water environment may cause public health problems, particularly with regard to the use of contaminated water for drinking, recreation, park irrigation, and road washing etc.(Meleg et al. 2006; Rutjes et al. 2009). Outbreaks of viral acute gastroenteritis by consumption of contaminated water have been frequently reported in the world, and viruses are known as the etiological agents for the infectious gastroenteritis 
(Divizia et al. 2004). While rotaviruses, astrovirus, and norovirus have been involved in these outbreaks (Hung et al. I984; Boccia et al. 2002; Divizia et al. 2004; Hoebe et al. 2004; Gallay et al. 2006; Hewitt et al. 2007; Martinelli et al. 2007; Maunula et al. 2009), routine procedures for monitoring these viruses in water samples had not been drawn up for the water-microbiology screening panel. Sewage water contains much higher numbers of viruses (Meleg et al. 2006) and sewage workers frequently exposed to raw sewage were found to be at higher risk of intestinal disease (Rylander I999; Venczel et al. 2003). The effluent with enteric pathogens from the sewerage systems, which directly entered into the water environment, was found to be one of the most important causes of waterborne outbreak (Hafliger et al. 2000), therefore, Sewerage systems should be regarded as an important nodes to monitor and control human enteric pathogens transmission(Katayama et al. 2008). Consequently, viral contamination resulting from the use of these treated waters will produce a risk that needs to be addressed (Arraj et al. 2008). Information on the monthly concentration distribution of enteric viruses in sewage treatment plants (STPs) will be useful, not only for understanding their fate but also for assessing the risk of infection through different exposure scenarios (Katayama et al. 2008).

In Beijing, the treated water from STPs, regarded as a second source water, had been widely used as toilet flushing water, industrial process water, environmental water, garden water and road washing water (He et al. 2008). Viruses discharged from STPs represent a risk of infection via various exposure processes such as the reuse of water for park irrigation or road sprinkling. An important step in addressing the safety of reused wastewater was to determine likely risks through exposure to treated water. A sound understanding of such risks will be not only of significant value in managing low-technology reuse schemes but form the basis of risk assessments for advanced reuse proposals (Hamilton et al. 2006).

Different types of filters and filtration methods, such as cartridge filters, glass wool filters, cation-coated filter, silica etc., had been used to collect and concentrate rotavirus, astrovirus, and norovirus from sewage water samples (Baggi et al. 200I; van Zyl et al. 2004; Katayama et al. 2008). Traditional methods such as cell culture for enteric virus detection remained cumbersome, costly and time-consuming (Jean et al. 2002). Recently, more molecular approaches had been used to detect rotavirus, astrovirus, and norovirus from sewage water samples (Baggi et al. 200r; Jean et al. 2002; Meleg et al. 2006; Min et al. 2006; He et al. 2008; Katayama et al. 2008).
In China, most studies focused on the epidemiologic characteristics of viral diarrhea in hospitals. However, knowledge of the occurrence of rotavirus, astrovirus, and norovirus in water environment was very limited. The goal of this study was to assess viral contamination of the three viruses responsible for acute gastroenteritis (RV, AV, and NV) from the urban STPs in Beijing. The obtained quantitative data of RV were used to provide a rough estimate of the risk of infection from occupational and accidental exposure to treated waters in Beijing.

\section{MATERIALS AND METHODS}

\section{Collection of water samples}

From November 2006 to October 2007, influent and effluent samples were collected monthly for one year and 96 water samples were drawn totally from three urban STPs. The three municipal STPs received complex mixtures of industrial and domestic sewage with a treatment capacity of $1(\mathrm{~A}), 0.04(\mathrm{~B})$ and $0.1(\mathrm{C})$ million tons per daily, respectively. All the three plants used activated sludge and included a sedimentation step at the end of the process, and in plant An and C, part of the secondary effluent was further treated by coagulant and micro-filtration, respectively, resulting in reclaimed effluent (He et al. 2008).

We have taken 36 samples $(1 \mathrm{~mL})$ from influents, 36 samples $(1 \mathrm{~L})$ from effluents of secondary treatment, as well as 24 samples $(1 \mathrm{~L})$ from reclaimed treatment. All samples were processed within $12 \mathrm{~h}$ after collection. The method used for the concentration of water samples was described previously(He et al. 2008).

\section{Extraction of nucleic acids from water specimens}

RNA was extracted using the Qiagen viral RNA extraction kit (QIAgen, Germany) following the manufacturer's instruction. The $50 \mu \mathrm{l}$ RNA eluates were stored at -80 until amplification of nucleic acid was performed.

\section{Detection of rotavirus, astrovirus and norovirus in water samples}

Primer characteristics and references for the amplification conditions of different PCR or nested PCR protocols used for nucleic acid detection of rotavirus, astrovirus, and norovirus were all described previously (Liu et al. 2006; He et al. 2008). Briefly primers END9, R1, R3, and Rp were used for the amplification of sequences from the VP7 gene of group A 
rotaviruses. Norovirus was analyzed using RT-PCR with primers JV12a and JV13b. Astrovirus was detected by RTPCR with primers Mon 269 and Mon 270. To avoid falsepositive results, quality control measures were followed as recommended and for each set of amplifications, negative and positive control samples were included. All methodologies were standardized with reference strains of each virus. In the present study, previously characterized virus strains obtained from fecal samples were used as positive controls. The PCR products were resolved on 1.8\% agarose gel, followed by ethidium bromide staining $(0.5 \mathrm{mg} / \mathrm{mL})$, and images were obtained with the image capture system (BioRad) with the Quantity One software program. PCR products were sequenced at the Chinese National Human Genome Center, Beijing using the same primers. The sequences were aligned and searched for nearly identical sequences using the Basic Local Alignment Search Tool (blast) program available on the NCBI network server.

\section{Quantitative detection of rotavirus genomes in water samples}

Real-time PCR was performed in a MX3005P real-time quantitative polymerase chain reaction system (Stratagene, USA) in a total volume of $25 \mu \mathrm{L}$, consisting of the Brilliant II SYBR Green QPCR master mix (Stratagene, USA) , $300 \mathrm{nM}$ forward primer R3 and $300 \mathrm{nM}$ reverse primer Rp (Baggi \& Peduzzi 2000). The thermal cycling conditions were as follows: an initial denaturation at $95^{\circ} \mathrm{C}$ for $10 \mathrm{~min}$ followed by 45 cycles of $30 \mathrm{~s}$ at $95^{\circ} \mathrm{C}, 40 \mathrm{~s}$ at $50^{\circ} \mathrm{C}$ and $30 \mathrm{~s}$ at $72^{\circ} \mathrm{C}$. Each run ended with a melting curve analysis. Fluorescence data were collected at the end of each cycle, and determination of the cycle threshold line was carried out automatically by the instrument. PCR amplicons that were positive with SYBR green real-time PCR were further analyzed by gel electrophoresis through $1.8 \%$ agarose gels to confirm the amplicon size.

In order to make a standard curve, standard samples of rotavirus-DNA plasmid $\left(10^{15}\right.$ copies $\left./ \mu \mathrm{L}\right)$ were diluted by serial 10-fold dilution. The water and standard samples were subjected to real-time PCR simultaneously, followed by analysis using Mx3000P software (Stratagene) to obtain quantitative data on the concentration of rotavirus cDNA in a well. Three wells were used for the water and standard samples, respectively, and the average was used for subsequent calculations.

\section{Risk assessment}

For both professional and accidental contact with secondary effluent and/or reclaimed water during road sprinkling and park irrigation in Beijing, the risk of infection with rotavirus per exposure event was estimated. The probability of an infection $\left(P_{\mathrm{i}}\right)$ resulted from ingestion of some number of rotavirus was calculated based on the beta-Poisson model (Gerba et al. 1996). Yearly infection risks were calculated using the following equation: $P_{\mathrm{a}}=1-\left(1-P_{\mathrm{i}}\right)^{n}$, where $n$ is the exposure frequency in one year. The range of estimated ingested volumes per contact event used and the exposure frequency in one year in the calculations was based on the results obtained in a survey of water ingestion (He et al. 2006a). In this study, we assumed that rotavirus genomes detected were 1000 times more abundantly present than infectious rotavirus particles(Rutjes et al. 2009).

\section{RESULTS}

\section{Profile of rotavirus, astrovirus and norovirus in sewage samples}

Viruses could be detected in 35.4\% (34/96) of the water samples analyzed. Rotavirus was the most frequently detectable $(32.3 \%, 31 / 96)$, followed by human astrovirus $(6.3 \%$, $6 / 96)$ and human norovirus $(3.1 \%, 3 / 96)$. All positive samples gave the correct sequence after using blast on NCBI. In plant $\mathrm{A}$, all three viruses were detected and rotavirus was the most in frequency $(36.1 \%, 13 / 36)$. No astrovirus was detected in plant C. And no norovirus was detected in plant B. Rotaviruses were detected in $44.4 \%$ ( $16 / 36 \square$ of the influent samples and $25 \%(17 / 60)$ of the effluent samples from three STPs. The seasonal distributions of rotavirus, astrovirus and norovirus in influent and effluent samples from the three plants are shown in Figure 1. It was observed that the positive

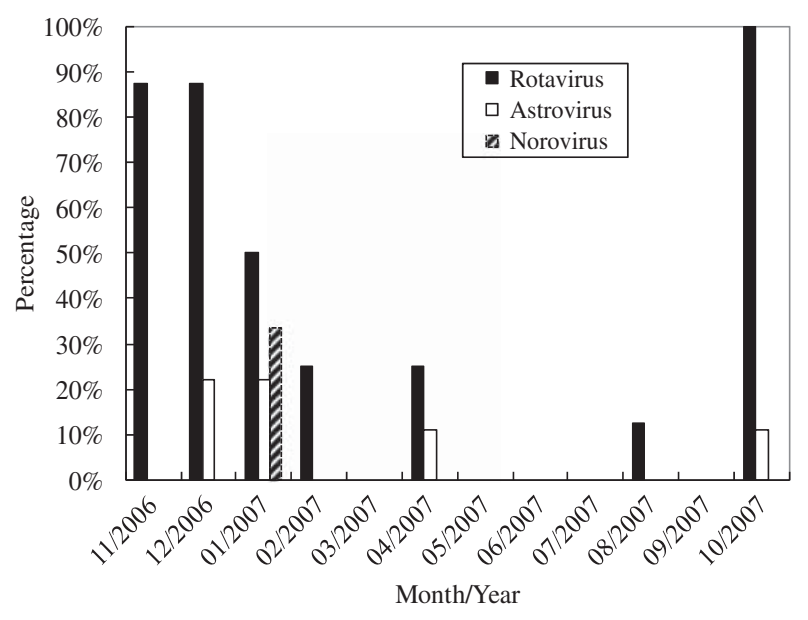

Figure 1 | Distribution of rotavirus, astrovirus and norovirus in sewage samples. 
signals for rotavirus occurred in all samples taken between winter and spring (from October to April), and was less detectable during summer (from June to August). The highest percentage of positive detection for rotaviruses occurred in October 2007 (100\%), followed by November 2006 (87.5\%) and December 2006 (87.5\%). All positive detections for astroviruses were found in winter and spring (December, January, April and October). Three positive detections for noroviruses were all in February 2007.

\section{Quantitative survey of rotavirus genomes in sewage samples}

The genomes of rotavirus in samples of positive detection were further quantified by real time PCR. Melting curve analysis was undertaken for the amplified DNA. The rotavirus real time PCR gave distinct melting curve diagrams, indicating that the PCR product was that of the human rotavirus sequence and thus the primers used in the study were specific for human rotavirus (Figure 2A). The efficiency of replication was $99 \%$ falling within the requested range of 90\%-110\%. A good linear relationship was consistently observed with rotavirus cDNA ranging from $3.62 \times 10^{2}$ to $3.62 \times 10^{6}$ copies per reaction with a mean correlation coefficient of 0.999 in three independent runs. All the Ct values from the sewage samples fall within the range of linearity. Gel electrophoresis also confirmed that DNA of the expected size was amplified using the human rotavirus cDNA standard and the human rotavirus positive sample (Figure 2B). In contrast, other non-specific products were not observed.

The quantitative detections of rotavirus in three STPs were carried out for each month of one year period, from November 2006 to October 2007. The seasonal profile of rotaviruses in influent, secondary effluent and reclaimed

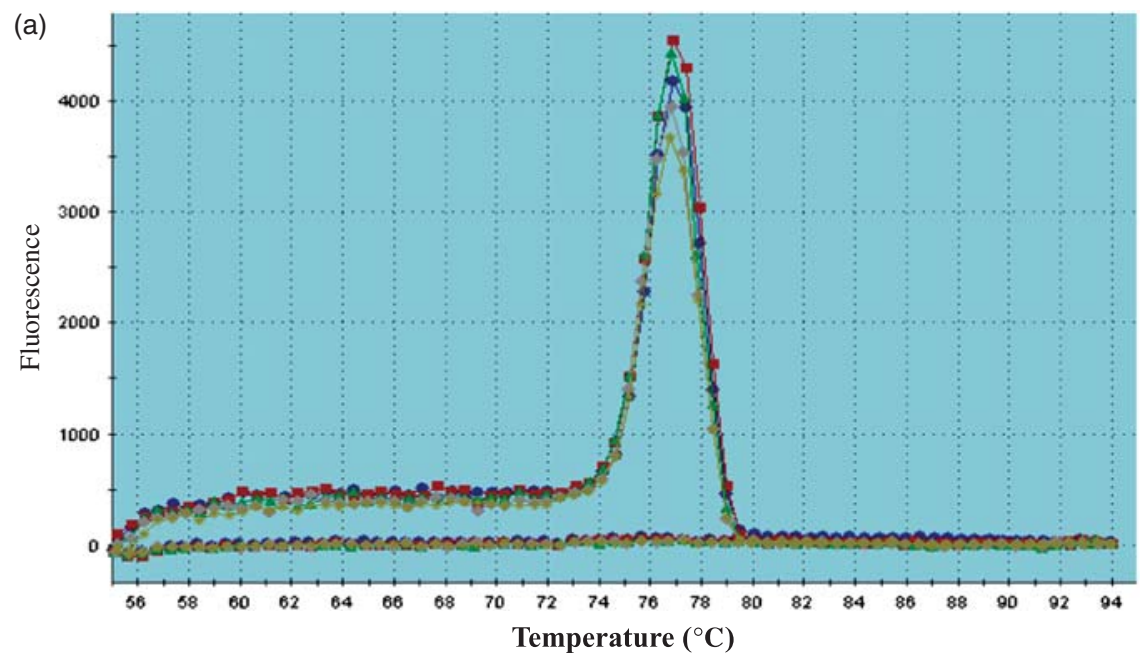

(b)

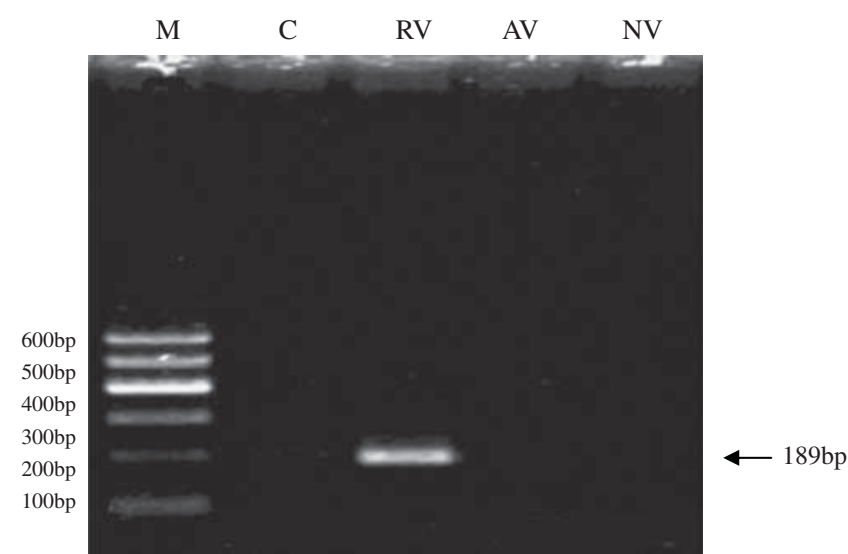

Figure 2 Specificity of the real-time PCR: (A) melting curve analyses for RV (B) Agarose gel electrophoresis of amplified products. Lanes: M, 100 bp DNA ladder; C, negative control; RV, rotavirus; AV, Astrovirus; NV, Norovirus.The positive band denotes 189 bp products. Subscribers to the online version of Water Science and Technology can access the colour version of this figure from http://www.iwaponline.com/wst. 

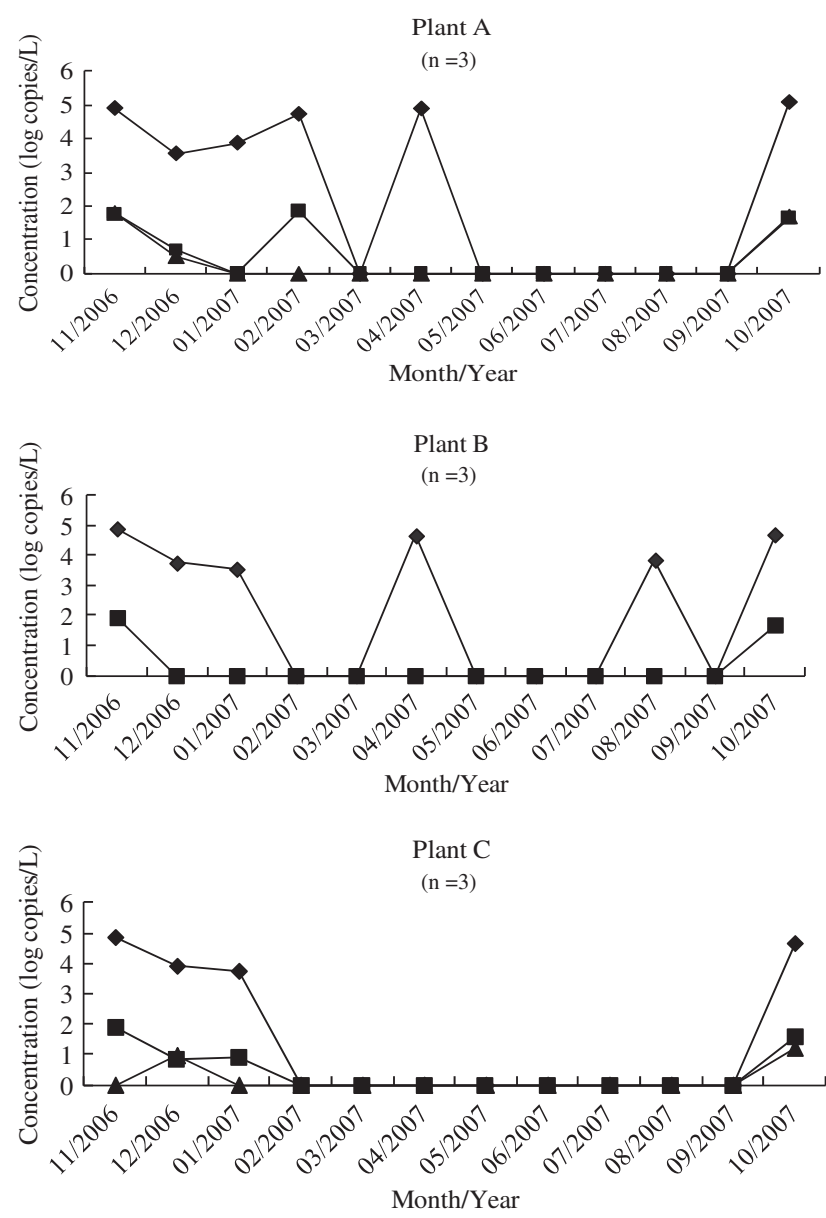

Figure 3 Seasonal profile of rotaviruses at three STPS. ( $\square$ ) Influent ( $\square$ ) Secondary effluent (A) Reclaimed water.

water were shown in Figure 3. As it was shown, the concentrations of rotavirus in influents of three STPs were quite similar, i.e., abundant in cold seasons (3.68, 2.82 and $2.86 \log$ copies $\mathrm{L}^{-1}$ on average, respectively, from October to March), and less in warm seasons $\left(0.81,1.42\right.$ and $0 \log$ copies $\mathrm{L}^{-1}$ on average, respectively, from April to September). In secondary effluents, abundance of rotavirus were lower than that in influent, e.g., 1.0, 0.6 and $0.88 \log$ copies $\mathrm{L}^{-1}$ in cold weather on average, respectively, and no detection in warm seasons. The distribution profiles in reclaimed water showed also seasonal variation and the concentrations were the highest (0.67 and $0.36 \log$ copies $\mathrm{L}^{-1}$ on average in plant An and plant C, respectively) during cold weather. No virus was detected during warm seasons in reclaimed water.

\section{Potential health risk exposure to rotavirus in treated waters}

Estimated average volumes of water ingested by occupational worker of road sprinkling $(77 \mathrm{ml})$ and park irrigation $(58 \mathrm{ml})$ one day were used to calculate the risk of infection with rotavirus for an exposed occupational individual(He et al. $2006 \mathrm{~b})$. The estimated average volumes of water ingested one day for passerby during road sprinkling were $10 \mathrm{ml}$ and for young and old during park irrigation were 40 and $50 \mathrm{ml}$, respectively(He et al. 2006b).

The $P_{\mathrm{a}}$ value at ingestion of 10 to $77 \mathrm{ml}$ water ranged from $5.0 \times 10^{-4}$ to $1.0 \times 10^{-1}$ based on the average detected rotavirus concentrations in three STPs (Table 1). And maximum rotavirus concentrations resulted in a $P_{\mathrm{a}}$ value of $9.1 \times 10^{-3}$ to $4.5 \times 10^{-1}$ (Table 1 ). For the occupational workers, the maximum virus concentration resulted in an estimated $P_{\mathrm{a}}$ value of $4.5 \times 10^{-1}$ during road sprinkling, whereas during park irrigation the maximum virus concentration led to an estimated $P_{\mathrm{a}}$ value of $2.8 \times 10^{-2}$ if secondary effluents were used directly (plant B). To non-occupational people, the maximum virus concentration resulted in an estimated $P_{\mathrm{a}}$ of $1.0 \times 10^{-1}$ during road sprinkling, whereas

Table 1 | Rotavirus infection risk per year by effluents from three municipal STPS

Road sprinkling

\begin{tabular}{|c|c|c|c|c|c|c|c|c|c|c|c|}
\hline & & & & & & & & Nonoccup & ional & & \\
\hline & & Occupati & al passerby & & & Occupati & & Young & & Old & \\
\hline & Sampling sites & $\operatorname{Max}$ & Mean & $\operatorname{Max}$ & Mean & $\operatorname{Max}$ & Mean & $\operatorname{Max}$ & Mean & $\operatorname{Max}$ & Mean \\
\hline A & Secondary effluent & 0.3965 & 0.1036 & 0.0882 & 0.0197 & 0.0235 & 0.0051 & 0.0162 & 0.0035 & 0.0203 & 0.0044 \\
\hline & Reclaimed water & 0.3682 & 0.0682 & 0.0805 & 0.0127 & 0.0213 & 0.0033 & 0.0148 & 0.0023 & 0.0184 & 0.0028 \\
\hline B & Secondary effluent & 0.4509 & 0.0758 & 0.1039 & 0.0142 & 0.0278 & 0.0037 & 0.0193 & 0.0025 & 0.0240 & 0.0032 \\
\hline $\mathrm{C}$ & Secondary effluent & 0.4341 & 0.0775 & 0.0989 & 0.0146 & 0.0264 & 0.0038 & 0.0183 & 0.0026 & 0.0228 & 0.0032 \\
\hline & Reclaimed water & 0.2469 & 0.0143 & 0.0504 & 0.0026 & 0.0132 & 0.0007 & 0.0091 & 0.0005 & 0.0114 & 0.0006 \\
\hline
\end{tabular}


the maximum virus concentration led to an infection risk of $2.4 \times 10^{-2}$ during park irrigation. The infection risks for people who were accidentally exposed to the water were generally lower, because they swallowed less water than occupational workers.

\section{$\overline{\text { DISCUSSION }}$}

For the first time, the monthly distributions of rotavirus, astrovirus and norovirus in wastewater and in the reclaimed water were surveyed quantitatively in China. The detection frequencies for rotavirus, astrovirus and norovirus were $30.6 \%, 5.6 \%$ and $2.8 \%$, respectively, which were in accordance with the reported infection frequencies of $59 \%, 8 \%$ and $6 \%$ by rotavirus, astrovirus and norovirus, respectively (Liu et al. 2006). Three viruses were detected mostly in winter, which supported epidemiological reports that these viruses were more frequently detected in hospitalized patients' feces in the winter. It was very difficult to eliminate the three viruses of the influents by the sewerage system and the three viruses also occurred in the secondary and tertiary effluents of the sewerage system, which demonstrated the permanence property of the three viruses and the dissemination possibility by the reused effluent water of sewerage system.

The present study showed a higher prevalence of rotavirus, astrovirus and norovirus during the cold seasons, but the difference was statistically significant only for rotavirus. Increased viral stability in the environment due to lowered temperature, as found in studies on some enteric viruses, could promote waterborne gastroenteritis during winter, and thereby a higher viral load in sewage (Myrmel et al. 2006).

The prevalence of positive PCRs for rotaviruses was similar compared with some previous studies. For example, a study in Oslo from Norway reported that rotaviruses were detected in $38 \%, 72 \%$ and $83 \%$ of the inlet samples and $36 \%$, $56 \%$ and $68 \%$ of the outlet samples from three STPs by RT-nested PCR(Myrmel et al. 2006). In Bangkok, 25\% of the sewage samples were positive for rotavirus using RT-nested PCR(Kittigul et al. 2005). A RT-PCR hybridization was used in a study from Barcelona and Cairo, where $66.9 \%$ and $85.7 \%$ of sewage samples were positive for rotavirus, respectively (Villena et al. 2003). A study in France reported a prevalence of rotavirus in raw sewage of 42\% (Dubois et al. 1997).

The positive samples for detectable astrovirus and norovirus were rare in present study. A similar study in Norway, however, reported a higher prevalence of astrovirus in raw sewage of 46-94\%(Myrmel et al. 2006). A study on astrovirus in Hungary also showed a relatively high prevalence
(43\%)(Meleg et al. 2006). Tajima et al. (2007) reported that norovirus was detected in 20 of 22 specimens (91\%) in the secondary effluent and 20 of 28 specimens (71\%) in the reclaimed water after tertiary treatments. In a study from the Netherlands (Lodder \& de Roda Husman 2005), the concentration of norovirus in sewage was higher than that of rotavirus. The difference might be attributed to the epidemiological situation, the method used to concentrate the viruses, or even to the primer sets used for detection.

In this study, the concentration of rotaviruses in influent of the three STPs in Beijing was quantitatively determined monthly for a year, which indicated that rotaviruses infections should occur in the service area of the STPs. The data also suggested that a virus detection of the influent in a STP would be an appropriate measure to understand the exact occurrence of viruses in the area.

For the purposes of risk assessment, rotavirus was chosen as the model organism. Rotavirus was a subgroup of enteric viruses that were known to cause gastroenteritis. It was highly infectious (Parashar et al. 2003) and has been widely used as a representative organism for enteric viruses in risk assessment of wastewater reuse (Hamilton et al. 2006; Seidu et al. 2008). Detection of viral genomes may be considered insufficient to identify infectious risk for the human population (Gassilloud et al. 2003; Rutjes et al. 2009). In this study, it was assumed that $1 / 1000$ of rotavirus genomes detected were infectious rotavirus particles though it may underestimate the health risks (Rutjes et al. 2009). A disease risk of $10^{-3}$ per person per year, which was used by WHO as the tolerable risk of waterborne disease from drinking fully treated drinking water, was unduly cautious (Haas 1996). It means one occurrence of disease per person per 1,000 years (for a community this risk of $10^{-3}$ means that every year $0.1 \%$ of the community becomes diseased as a result of drinking fully treated drinking water) (Mara et al. 2007). A more acceptable level for the risk of infection (rather than of disease) is $10^{-2}$ (i.e. once in every 100 years, essentially once in a lifetime; or $1 \%$ of the community per year)(Mara et al. 2007). Even this level of risk is relatively cautious, given the much higher actual incidence of diarrheal disease occurring in both industrialized and developing countries. In our study, a risk of rotavirus infection per year of $10^{-2}$ was used as the reference level of acceptable risk (Seidu et al. 2008). The observed maximum $P_{\mathrm{a}}$ value was $4.5 \times 10^{-1}$, which was much higher than this acceptance level. All the $P_{\mathrm{a}}$ value during road sprinkling and $46.9 \%$ of $P_{\mathrm{a}}$ value during park irrigation exceeded the line of $10^{-2}$. Based on this assumption, the results indicated that there was a certain health risk for both occupational works and people who were accidentally exposed to rotaviruses in the effluents 
of STPs. A study in Uganda also showed a higher infection risk per year $\left(8.87 \times 10^{-1}\right.$ and $\left.9.85 \times 10^{-1}\right)($ Howard et al. 2006).The estimated risks from rotavirus infections recorded in this assessment should be interpreted with some caution. The health risks presented here should not be misconstrued as a representative for all the possible enteric virus infections because of the diverse symptoms of enteric virus infections (Seidu et al. 2008).

The results of this study illustrated the presence of waterborne viruses in sewage water systems of Beijing and showed that both occupational and accidental exposure to rotaviruses in treated water may pose a health risk. The present results demonstrated the benefits of employing a more advanced treatment of sewage (Myrmel et al. 2006). The reduction of viruses in STPs will directly contribute to reducing viruses in the environment and accordingly result in the reduction of infection risk.

In conclusion, this study provided the first direct evidence that human viruses were prevalent in sewage water systems in Beijing and showed that both occupational and accidental exposure to rotaviruses in treated water may pose a health risk.

\section{ACKNOWLEDGEMENTS}

This work was supported by the National Key Technology R\&D Program (2008ZX07314-003; 2009ZX07527-005), National High Technology Research and Development Program (2008AA062501, 2008AA06A414), National S\&T Major Project (2006BAD01B06-03; 2006BAJ08B02), and the Foundation of State Key Laboratory of Environmental Aquatic Chemistry (2009-001).

\section{REFERENCES}

Arraj, A., Bohatier, J., Aumeran, C., Bailly, J. L., Laveran, H. \& Traore, O. 2008 An epidemiological study of enteric viruses in sewage with molecular characterization by RT-PCR and sequence analysis. J. Water Health 6, 351-358.

Baggi, F., Demarta, A. \& Peduzzi, R. 20or Persistence of viral pathogens and bacteriophages during sewage treatment: lack of correlation with indicator bacteria. Res. in Microbiol. 152, 743-751.

Baggi, F. \& Peduzzi, R. 2000 Genotyping of Rotaviruses in Environmental Water and Stool Samples in Southern Switzerland by Nucleotide Sequence Analysis of 189 Base Pairs at the 5' End of the VP7 Gene. J. Clin Microbiol. 38, 3681-3685.

Boccia, D., Tozzi, A. E., Cotter, B., Rizzo, C., Russo, T., Buttinelli, G., Caprioli, A., Marziano, M. L. \& Ruggeri, F. M. 2002 Waterborne Outbreak of Norwalk-Like Virus Gastroenteritis at a Tourist Resort, Italy. Emerg. Infect. Dis. 8, 563-568.
Deng, L., Jia, L. Y., Chen, D. M., Zhang, Y. \& Qian, Y. 2007 Clinical manifestations of norovirus gastroenteritis in infants and children. Zhonghua Liu Xing Bing Xue Za Zhi 28, 676-678.

Divizia, M., Gabrieli, R., Donia, D., Macaluso, A., Bosch, A., Guix, S., Sanchez, G., Villena, C., Pinto, R. M., Palombi, L., Buonuomo, E., Cenko, F., Leno, L., Bebeci, D. \& Bino, S. 2004 Waterborne gastroenteritis outbreak in Albania. Water Sci. Technol. 50(1), 57-61.

Dubois, E., Le Guyader, F., Haugarreau, L., Kopecka, H., Cormier, M. \& Pommepuy, M. 1997 Molecular epidemiological survey of rotaviruses in sewage by reverse transcriptase seminested PCR and restriction fragment length polymorphism assay. Appl. Environ. Microbiol. 63,1794-1800.

Fang, Z. Y., Sun Y. P., Ye, X. H., Wang, H., Zhang, Q., Duan, Z. J., J, X. i., Steele, D. \& Glass, R. 2006 Astrovirus infection among hospitalized children with acute diarrhea in seven regions of China, 1998-2005. Zhonghua Liu Xing Bing Xue Za Zhi 27, 673-676.

Gallay, A., De Valk, H., Cournot, M., Ladeuil, B., Hemery, C., Castor, C., Bon, F., Megraud, F., Le Cann, P. \& Desenclos, J. 2006 A large multi-pathogen waterborne community outbreak linked to faecal contamination of a groundwater system, France, 2000. Clin. Microbiol. Infect. 12, 561-570.

Gassilloud, B., Schwartzbrod, L. \& Gantzer, C. 2003 Presence of viral genomes in mineral water: a sufficient condition to assume infectious risk. Appl. Environ. Microbiol. 69, 3965-3969.

Gerba, C., Rose, J., Haas, C. \& Crabtree, K. 1996 Waterborne rotavirus: a risk assessment. Water Res. 30, 2929-2940.

Haas, C. 1996 Viewpoint: acceptable health risk. J. Am. Water Works Ass. 88, 8.

Hafliger, D., Hübner, P. \& Lüthy, J. 2000 Outbreak of viral gastroenteritis due to sewage-contaminated drinking water. Int. J. Food Microbiol. 54, 123-126.

Hamilton, A., Stagnitti, F., Premier, R., Boland, A. \& Hale, G. 2006 Quantitative microbial risk assessment models for consumption of raw vegetables irrigated with reclaimed water. Appl. Environ. Microbiol. 72, 3284-3290.

He, X. H., Ma, S. H. \& Li, A. D. 2006a Concentration limitations of pathogenic microorganisms in reclaimed water. Huan Jing Ke Xue 27, 1402-1405.

He, X. H., Ma, S. H., Li, A. D., Pan, X. C., Chen, Q. \& Wang, J. F. 2006b Exposure assessment of various reclaimed water uses. Huan Jing Ke Xue 27, 1912-1915.

He, X. Q., Cheng, L., Li, W., Xie, X. M., Ma, M. \& Wang, Z. J. 2008 Detection and distribution of rotavirus in municipal sewage treatment plants (STPs) and surface water in Beijing. J. Environ. Sci. Health A. Tox. Hazard Subst. Environ. Eng. 43, 424-429.

Hewitt, J., Bell, D., Simmons, G. C., Rivera-Aban, M., Wolf, S. \& Greening, G. E. 2007 Gastroenteritis outbreak caused by waterborne norovirus at a New Zealand ski resort. Appl. Environ. Microbiol. 73, 7853-7857.

Hoebe, C. J., Vennema, H., de Roda Husman, A. M. \& van Duynhoven, Y. T. 2004 Norovirus outbreak among primary school children who had played in a recreational water fountain. J. Infect. Dis. 189, 699-705.

Howard, G., Pedley, S. \& Tibatemwa, S. 2006 Quantitative microbial risk assessment to estimate health risks attributable to water supply: can the technique be applied in developing countries with limited data? J. Water Health 4, 49-65. 
Hung, T., Chen, G. M., Wang, C. G., Yao, H. L., Fang, Z. Y., Chao, T. X., Chou, Z. Y., Ye, W., Chang, X. J., Den, S. S. \& 1984 Waterborne outbreak of rotavirus diarrhoea in adults in China caused by a novel rotavirus. Lancet 1, 1139-1142.

Jean, J., Blais, B., Darveau, A. \& Fliss, I. 2002 Rapid detection of human rotavirus using colorimetric nucleic acid sequence-based amplification (NASBA)-enzyme-linked immunosorbent assay in sewage treatment effluent. FEMS Microbiol. Lett. 210, 143-147.

Jia, L. P., Qian, Y., Zhang, Y., Chen, D. M., Gao, Y. \& Xu, Q. 2007 Norovirus associated outbreaks of acute gastroenteritis in hospitals in Beijing in late 2006. Zhonghua Liu Xing Bing Xue Za Zhi 28, 213-217.

Katayama, H., Haramoto, E., Oguma, K., Yamashita, H., Tajima, A., Nakajima, H. \& Ohgaki, S. 2008 One-year monthly quantitative survey of noroviruses, enteroviruses, and adenoviruses in wastewater collected from six plants in Japan. Water Res. 42, 1441-1448.

Kittigul, L., Ekchaloemkiet, S., Utrarachkij, F., Siripanichgon, K., Sujirarat, D., Pungchitton, S. \& Boonthum, A. 2005 An efficient virus concentration method and RT-nested PCR for detection of rotaviruses in environmental water samples. J. Virol. Methods 124, $117-122$.

Liu, C., Grillner, L., Jonsson, K., Linde, A., Shen, K., Lindell, A. T., Wirgart, B. Z. \& Johansen, K. 2006 Identification of viral agents associated with diarrhea in young children during a winter season in Beijing. China. J. Clin. Virol. 35, 69-72.

Lodder, W. J. \& de Roda Husman, A. M. 2005 Presence of Noroviruses and Other Enteric Viruses in Sewage and Surface Waters in The Netherlands. Appl. Environ. Microbiol. 71, 1453-1461.

Mara, D., Sleigh, P., Blumenthal, U. \& Carr, R. 2007 Health risks in wastewater irrigation: comparing estimates from quantitative microbial risk analyses and epidemiological studies. J. Water Health 5, 39-50.

Martinelli, D., Prato, R., Chironna, M., Sallustio, A., Caputi, G., Conversano, M., Ciofi, D., D’Ancona, F., Germinario, C. \& Quarto, M. 2007 Large outbreak of viral gastroenteritis caused by contaminated drinking water in Apulia, Italy, May-October 2006. Euro. surveillance 12, E070419.1.

Maunula, L., Klemola, P., Kauppinen, A., derberg, K. S., Nguyen, T., Pitk nen, T., Kaijalainen, S., Simonen, M., Miettinen, I. \& Lappalainen, M. 2009 Enteric Viruses in a Large Waterborne Outbreak of Acute Gastroenteritis in Finland. Food Environ. Virol. 1, 31-36.

Meleg, E., Jakab, F., Kocsis, B., Banyai, K., Melegh, B. \& Szucs, G. 2006 Human astroviruses in raw sewage samples in Hungary. J. Appl. Microbiol. 101, 1123-1129.
Min, B., Noh, Y., Shin, J., Baek, S., Min, K., Ryu, S., Kim, B., Park, M., Choi, S., \& Yang, E. 2006 Assessment of the quantitative real-time polymerase chain reaction using a cDNA standard for human group A rotavirus. J. Virol. Methods 137, 280-286.

Myrmel, M., Berg, E. M., Grinde, B. \& Rimstad, E. 2006 Enteric viruses in inlet and outlet samples from sewage treatment plants. J. Water Health 4, 197-209.

Parashar, U. D., Hummelman, E. G., Bresee, J. S., Miller, M. A. \& Glass, R. I. 2003 Global illness and deaths caused by rotavirus disease in children. Emerg. Infect. Dis. 9, 565-572.

Rutjes, S., Lodder, W., van Leeuwen, A. \& de Roda Husman, A. 2009 Detection of infectious rotavirus in naturally contaminated source waters for drinking water production. J Appl. Microbiol. 107, 97-105.

Rylander, R. I999 Health effects among workers in sewage treatment plants. British Medical Journal 56, 354-357.

Seidu, R., Heistad, A., Amoah, P., Drechsel, P., Jenssen, P. \& Stenstr m, T. 2008 Quantification of the health risk associated with wastewater reuse in Accra, Ghana: a contribution toward local guidelines. J. water health 6, 461-471.

Tong, Z. L., Ma, L., Zhang, J., Hou, A. C., Zheng, L. S., Jin, Z. P., Xie, H. P., Zhang, L. J., Ivanoff, B., Glass, R. I., Bresee, J. S., Jiang, X. I., Kilgore, P. E. \& Fang, Z. Y. 2003 Epidemiological study of rotavirus diarrhea in Beijing, China - a hospital-based surveillance from 1998 - 2001. Zhonghua Liu Xing Bing Xue Za Zhi 24, $1100-1103$.

van Zyl, W. B., Williams, P. J., Grabow, W. O. \& Taylor, M. B. 2004 Application of a molecular method for the detection of group A rotaviruses in raw and treated water. Water Sci Technol 50(1), 223-228.

Venczel, L., Brown, S., Frumkin, H., Simmonds-Diaz, J., Deitchman, S. \& Bell, B. 2003 Prevalence of hepatitis A virus infection among sewage workers in Georgia This article is a US Government work and, as such is in the public domain in the United States of America. Am. J. Ind. Med. 43, 172-178.

Villena, C., El-Senousy, W. M., Abad, F. X., Pinto, R. M. \& Bosch, A. 2003 Group A Rotavirus in Sewage Samples from Barcelona and Cairo: Emergence of Unusual Genotypes. Appl. Environ. Microbiol. 69, 3919-3923.

Zhang, L. J., Fang, Z. Y., Sun, L. W., Du, Z.-q., Tang, J. Y., Zeng, G., Steele, D., Kilgore, P., Jiang, X., Glass, R. \& Jiang, B. M. 2007 Rotavirus diarrhea among children in three hospitals under sentinel surveillance, from August 2001 to July 2004. Zhonghua Liu Xing Bing Xue Za Zhi 28, 473-476. 